Article

\title{
Cytomegaloviruses in a Community of Wild Nonhuman Primates in Taï National Park, Côte D'Ivoire
}

\author{
Augustin Etile Anoh ${ }^{1,2}$, Sripriya Murthy ${ }^{3}$, Chantal Akoua-Koffi ${ }^{2}$, Emmanuel Couacy-Hymann ${ }^{4}$, \\ Fabian Hubertus Leendertz ${ }^{5}$, Sébastien Calvignac-Spencer ${ }^{5,6, *,+}$ and Bernhard Ehlers ${ }^{3, *,+}$ \\ 1 UFR de Biosciences/Laboratoire de Zoologie et Biologie Animale, Université Felix Houphouët Boigny, \\ Abidjan BP 1174, Cote D'Ivoire; anohethyl@yahoo.fr \\ 2 Centre de Recherche pour le Développement, Université Alassane Ouattara, Bouaké BP 1174, Cote D’Ivoire; \\ Akouamc@yahoo.fr \\ 3 Division 12 Measles, Mumps, Rubella and Viruses Affecting Immunocompromised Patients, \\ Robert Koch Institute, Seestrasse 10,13353 Berlin, Germany; murthysripriya89@gmail.com \\ 4 Laboratoire National D'appui au Développement Agricole/Laboratoire Central de Pathologie Animale, \\ Bingerville BP 206, Cote D’Ivoire; chymann@hotmail.com \\ 5 Epidemiology of Highly Pathogenic Microorganisms, Robert Koch Institute, 13353 Berlin, Germany; \\ leendertzf@rki.de \\ 6 Viral Evolution, Robert Koch Institute, 13353 Berlin, Germany \\ * Correspondence: calvignacs@rki.de (S.C.-S.); ehlersb@rki.de (B.E.); \\ Tel.: +49-301-8754-2502 (S.C.-S.); +49-301-8754-2347 (B.E.) \\ + Shared senior authorship.
}

Received: 9 November 2017; Accepted: 20 December 2017; Published: 29 December 2017

\begin{abstract}
Cytomegaloviruses (CMVs) are known to infect many mammals, including a number of nonhuman primates (NHPs). However, most data available arose from studies led on captive individuals and little is known about CMV diversity in wild NHPs. Here, we analyzed a community of wild nonhuman primates (seven species) in Taï National Park (TNP), Côte d'Ivoire, with two PCR systems targeting betaherpesviruses. CMV DNA was detected in $17 / 87$ primates ( $4 / 7$ species). Six novel CMVs were identified in sooty mangabeys, Campbell's monkeys and Diana monkeys, respectively. In 3/17 positive individuals (from three NHP species), different CMVs were co-detected. A major part of the glycoprotein B coding sequences of the novel viruses was amplified and sequenced, and phylogenetic analyses were performed that included three previously discovered CMVs of western red colobus from TNP and published CMVs from other NHP species and geographic locations. We find that, despite this locally intensified sampling, NHP CMVs from TNP are completely host-specific, pinpointing the absence or rarity of cross-species transmission. We also show that on longer timescales the evolution of CMVs is characterized by frequent co-divergence with their hosts, although other processes, including lineage duplication and host switching, also have to be invoked to fully explain their evolutionary relationships.
\end{abstract}

Keywords: cytomegalovirus; nonhuman primate; genetic diversity; host specificity; co-divergence; Taï National Park; Côte d'Ivoire

\section{Introduction}

Cytomegaloviruses (CMVs; family Herpesviridae; genus Betaherpesvirinae) are viruses with a double-stranded DNA genome of $>200 \mathrm{kbp}$. In humans, CMV commonly causes asymptomatic infection in immunocompetent individuals, but the virus is a major cause of morbidity and mortality in newborns and immunosuppressed patients who are less able to counter primary infection or 
reactivation of latent virus [1-5]. Fever, hepatitis, pneumonia, dyspnea, gastrointestinal disorders (diarrhea), retinitis and neurological disorder are usually the clinical signs encountered [6,7]. CMVs also infect many nonhuman mammals, e.g., nonhuman primates (NHPs) and rodents. If and which diseases are caused by CMVs in NHPs is, to our knowledge, not known [8].

NHP CMVs have been detected by PCR and serology or isolated in cell culture mostly from captive individuals, i.e., hominines, including chimpanzees and orangutans $[9,10]$ and Old World monkey species, e.g., rhesus macaques [11], cynomolgus macaques [12], Formosan rock macaques [13], African green monkeys [14], drills [15], and baboons [16]. In very few studies, CMVs have been identified in wild NHPs, i.e., chimpanzees, gorillas and two species of colobus monkeys $[10,17,18]$. In all cases, CMVs infecting NHPs appeared to be host-specific.

However, infection studies in cell culture suggest that the species barrier for NHP CMVs is not absolute. Rhesus CMV displays some capacity to replicate in cells of other NHPs and in cells of human origin $[19,20]$. Chimpanzee CMV has been grown on human fibroblasts, lung and brain cells [21,22] and human CMV on chimpanzee fibroblasts [23]. One possible explanation for this discrepancy is that we know very little about CMV genetic diversity and their distribution in wild NHPs. First insight came from a recent study carried out in Taï National Park (TNP), Côte d'Ivoire, in which a primate predator-prey system-western chimpanzees (Pan troglodytes verus), and their primary (western red colobus; Piliocolobus badius) and secondary prey (black-and-white colobus; Colobus polykomos) —was used to study the risk of herpesvirus transmission between different primate species in the wild [17]. Although the colobus monkeys were frequently infected with CMVs and different gammaherpesviruses, there was no evidence for cross-species herpesvirus transmission, despite frequent exposure of the chimpanzees to their herpesvirus-infected monkey prey. It was suggested that interspecies transmission of beta- and gammaherpesviruses between members of different NHP species is at most a rare event in the wild. In a subsequent report, sequences of human CMVs, but no NHP CMVs, were detected in oral swabs and stool samples of human individuals living at the border of TNP [24]. This also suggests that zoonotic events are at most rare since people in the region still hunt and consume NHPs and are therefore also frequently exposed to infected NHP tissues [25]. Finally, fecal samples from central chimpanzees (Pan troglodytes troglodytes) and western lowland gorillas (Gorilla gorilla gorilla) from Odzala-Kokoua National Park (OKNP), Republic of Congo, were shown to be positive for CMVs of chimpanzee and gorilla, respectively, but negative for CMVs of other species [18].

Here we extended these tests for cross-species transmission of CMVs by targeting an entire wild primate community comprised of seven primate species living syntopically in TNP. Altogether, CMVs have been detected in six out of seven primate species including multiple CMV infections in single individuals, but no infection of multiple host species with the same CMV.

\section{Materials and Methods}

\subsection{Field sites and Sample Collection}

Necropsy and blood samples were collected over a period of more than 10 years from deceased or live individuals of $8 \mathrm{NHP}$ species (great apes and Old World monkeys); all necropsies were performed on carcasses detected opportunistically, i.e., no primate was culled for this project. Sampling was done in TNP in Cote d'Ivoire, the largest protected block of tropical moist forest in West Africa. Because of the history of anthrax and Ebola in NHP populations of TNP, full body protection suits and masks were required and mandatory for sampling. The field samples were initially snap frozen in liquid nitrogen and then stored at $-80^{\circ} \mathrm{C}$ at LANADA (Bingerville, Côte d'Ivoire), before being transported on dry ice to Robert Koch Institute, Germany. Collection of NHP samples was conducted with permission of the Ministry of Research of Côte d'Ivoire and the Office Ivoirien des Parcs et Réserves (OIPR). 


\subsection{DNA Extraction}

Total nucleic acid was extracted from necropsy samples (organs) and whole blood or buffy coat using the DNAeasy blood and tissue Kit (Qiagen, Hilden, Germany), according to the manufacturer's instructions. DNA concentration was quantified using Nanodrop ND-1000 Spectrophotometer (Nanodrop Technologies, Santa Clara, CA, USA) or Qubit (ThermoFischer, Waltham, MA, USA).

\subsection{Generic PCR}

For amplification of conserved NHP CMV UL55 and UL56 sequences, two independent generic nested PCRs were performed targeting either UL55 (glycoprotein B) (PCR 1; Figure 1A) or UL56 (PCR 2; Figure 1A) coding sequences using degenerate primer sets (Table S1). These primers had been designed in order to detect CMV-like betaherpesviruses, including those of NHP and humans. Using these primers, several primate and rodent CMV-like viruses have been discovered $[10,17,26]$. The PCRs were performed here as published previously $[17,25]$.

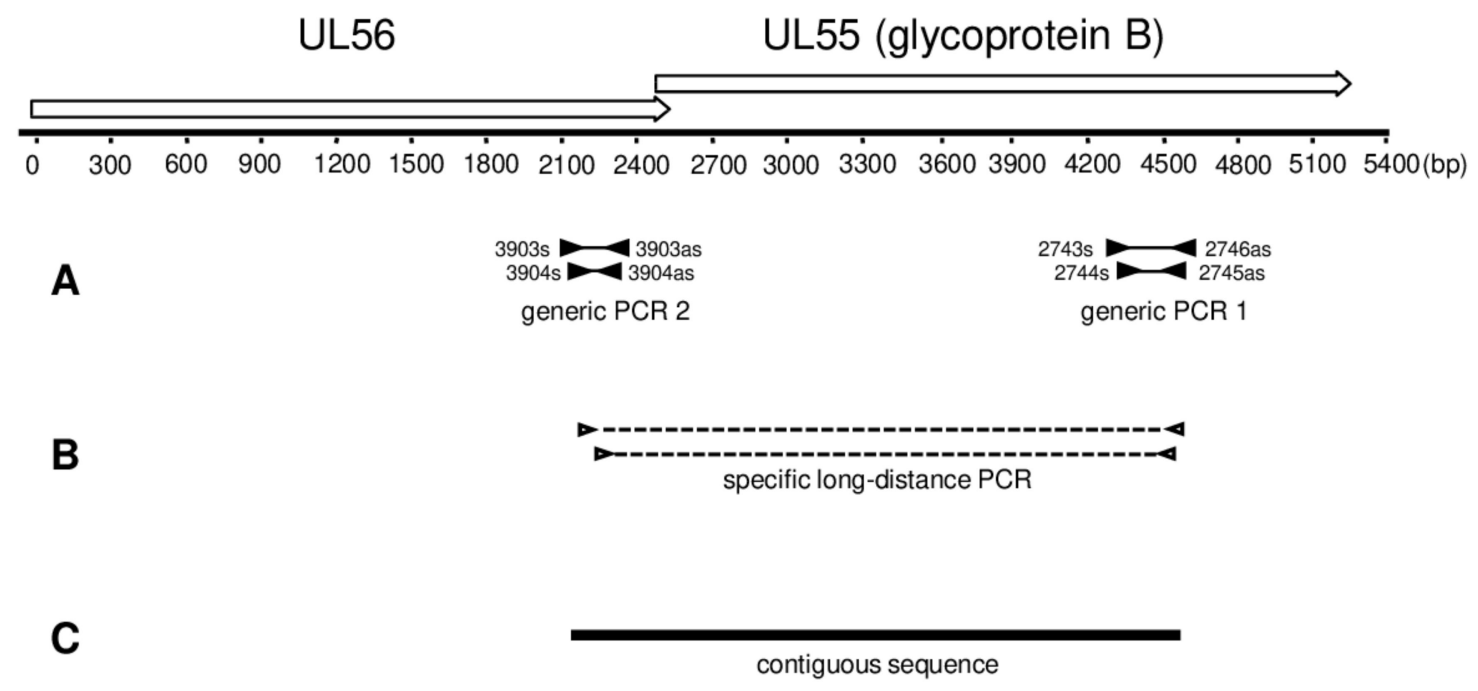

Figure 1. Map of targeted open reading frames and diagram of PCR strategy. Degenerate nested primers (black triangles) were used to amplify part of the UL55 or UL56 open reading frame. The amplified fragments are represented by thin solid lines between the primer binding sites (A); Long-distance nested PCR was performed with specific primers (open triangles). The amplified fragments are represented by dashed lines between the primer binding sites (B); Fragments amplified in $(\mathbf{A}, \mathbf{B})$ were sequenced and assembled to a final contiguous sequence of 2.2 to $2.4 \mathrm{~kb}(\mathbf{C})$. At the top of the figure, the genomic locus spanning open reading frames UL55 and UL56 is depicted with open arrows. The arrowhead indicates the direction of transcription. The start of the ruler corresponds to the first base of the ORF UL56.

\subsection{Long-Distance Nested PCR}

Long distance nested PCR was carried out using the TaKaRa-EX PCR kit (Takara Bio Inc., Otsu, Japan) according to the manufacturer's instructions, with an annealing temperature of $50^{\circ} \mathrm{C}$. Sequences of primers used are listed in Table S2. PCR mix was set up on ice and contained as template $250 \mathrm{ng}$ of DNA sample that tested positive for CMV with both PCR 1 and 2. Reaction product had a length of 2.2-2.3 kb (Figure 1B).

\subsection{Cytochrome B PCR}

The host species assignment of CMV-positive samples was confirmed by the PCR amplification of a fragment of the mitochondrial cytochrome $b(c y t b)$ gene, as done previously [26]. 


\subsection{Sequencing}

All PCR products were sequenced on both strands according to Sanger's methodology. For each novel virus, the sequences of PCR 1, PCR 2, and long-distance PCR were assembled to a final contiguous sequence of 2.2-2.4 kb (Figure 1).

\subsection{BLAST Analysis}

Blast search was undertaken in the NCBI database (www.ncbi.nlm.nih.gov/BLAST) [27].

\subsection{Phylogenetic and Co-Phylogenetic Analysis}

The translated amino acid UL55 sequences generated in the course of this study were aligned with other publicly available UL55 sequences derived from NHPs using Muscle [28] as implemented in Seaview v4 [29]. Conserved amino acid blocks were identified using gblocks (also implemented in Seaview) [30]. The final alignment included $36 \mathrm{CMV}$ sequences and one outgroup sequence (human herpesvirus 6B; KT246127); it was comprised of 543 positions. We then performed model selection using Prottest v2.4 [31], focusing on amino acid models available in BEAST (see below) and employing a full maximum likelihood (ML) optimization procedure. Using the Bayesian information criterion we identified $L G+G$ as the model to which our data were best-fit. We then ran phylogenetic analyses using both ML and Bayesian Markov chain Monte Carlo (BMCMC) approaches. For the ML analysis, we used PhyML v3 [32], as implemented on the PhyML webserver [33]; tree search was performed using the BEST algorithm and branch support was estimated using Shimodaira-Hasegawa-like approximate likelihood ratio tests (SH-like aLRT; [34]). BMCMC analyses were run using BEAST v1.8.2 assuming a relaxed lognormal molecular clock and modeling tree shape according to a birth-death speciation model [35]. The output of multiple runs was examined for convergence and appropriate sampling of the posterior with Tracer v1.6 (http:/ / tree.bio.ed.ac.uk/software/tracer/) before being merged using LogCombiner v1.8.2 (distributed with BEAST). The best representative tree was identified from the posterior set of trees and annotated with TreeAnnotator v1.8.2 (also distributed with BEAST).

We downloaded the host tree from the 10kTrees webserver [36]. The 10kTrees webserver provides pre-computed BMCMC timetrees for several taxa, including Primates.

We ran co-phylogenetic analyses using Jane v4 [37]. Jane implements a genetic algorithm to quickly identify the most parsimonious scenarios of co-evolution, involving several types of events (co-divergence, duplication, duplication with host switch, loss and failure to diverge). Host and parasite phylogenies have to be provided along with the according tip mapping and an event cost matrix. A simplified version of the CMV phylogeny was used as input, whereby single-host clades were collapsed; to be conservative regarding the number of co-speciation events, we used the ML tree, in which a couple of host-specific association identified by the BMCMC analysis were not supported. The cost set we used defined co-divergence events as having a cost -1 and all non co-divergence events as having no cost. This allows equating costs and co-divergence events. Jane was run using the vertex-based cost mode and the parameters of the genetic algorithm were kept at their default values (population size 100, number of generations 100). To determine the probability of observing the inferred costs by chance, costs were also calculated on a set of 500 samples for which tip mapping was randomized. Settings of the genetic algorithm were kept at default values.

\section{Results}

\subsection{Detection of Cytomegaloviruses in Wild Nonhuman Primates from TNP}

We tested DNA extracts from 87 NHP individuals (representing 7 NHP species; confirmed by cytochrome $b$ sequencing) for the presence of CMVs using a nested PCR sytem generic for members of the herpesvirus subfamily Betaherpesvirinae (nested PCR 1; Table S1 and Figure 1A). The sequences derived from the amplicons obtained were analyzed by BLASTN and BLASTX searches. The detection of CMV DNA was confirmed in 17/87 NHPs: 7/37 Cercocebus atys (sooty mangabey), 1/4 Cercopithecus 
campbelli (Campbell's monkey), 1/8 Cercopithecus diana (Diana monkey) and 9/18 Pan troglodytes verus (western chimpanzee) (Table 1).

Names and abbreviations for newly detected viruses were formed from host species and genus names to which the pathogen was assigned, the term "cytomegalovirus" and a consecutive number, e.g., Cercocebus atys cytomegalovirus 1 (CatyCMV1) (Table 2).

None of the Colobus polykomos, Perodicticus potto (potto) and Piliocolobus badius, individuals tested in this study were PCR-positive. However, positive black-and-white and red colobus individuals had been identified in a previous study led in TNP [17], which means we have now identified CMVs in $6 / 7$ NHP species living in this ecosystem (Table 2).

Except whole blood samples (PCR-negative), $10-28 \%$ of the organ and body fluid samples (kidney, liver, lung, spleen, heart, gastrointestinal tract, lymph node, buffy coat) were CMV-positive in nested PCR 1 (Table 3). In 3/17 CMV-positive individuals (from three NHP species), different viruses were detected in different tissues. Furthermore, PtroCMV1 and PtroCMV2 were co-detected in both spleen and liver of Pan troglodytes verus; CatyCMV1 and CatyCMV2 in both lung and liver of Cercocebus atys; CatyCMV1 and CatyROV1 in kidney of Cercocebus atys; CcamCMV1 and CcamCMV2 in kidney and duodenum of Cercopithecus campbelli. None of the viruses was detected in members of multiple species (Table 4).

We applied a two-step approach to extend the short partial UL55 (glycoprotein B encoding) sequences that had been amplified with nested PCR 1 , into the adjacent coding sequence (UL56). First, nested PCR 2 (which amplifies a short part of UL56 coding sequence; Table S1 and Figure 1a) was applied to all CMV-positive DNA extracts. This was successful for 20/23 DNA extracts (data not shown). Second, on the basis of the partial UL55 and UL56 sequences nested primers were specifically selected for each novel virus (Table S2) and used for overlapping long-distance nested PCR (LD-PCR) (Figure 1B), spanning 2.2-2.3 kb. Out of 20 extracts, 14 gave rise to the respective LD-PCR product. These products were purified and sequenced, and the LD-PCR sequences assembled with the short UL55 and UL56 sequences, to give final contigs of $2.23-2.39 \mathrm{~kb}$ that include $1.7-1.8 \mathrm{~kb}$ of the UL55 coding sequence (Figure 1C). These comprised all CMV-positive NHP species, and with the exception of CatyCMV3, all CMVs detected in this study (Table 2).

The novel CMV sequences were submitted to GenBank and are available under the accession numbers listed in Table 2.

\subsection{Phylogeny and Co-Phylogeny of Cytomegaloviruses and Their Hosts}

We used the new CMV sequences to investigate the diversification of CMV and more particularly how it was influenced by their host diversification. To compare the host and CMV diversification we generated phylogenetic trees from pre-computed resources (host phylogeny; Figure 2) or an alignment of CMV UL55 sequences comprising our new sequences and other publicly available sequences derived from nonhuman primates which we analyzed in a maximum likelihood or Bayesian framework (Figures 3 and 4, respectively).

CMV phylogenetic relationships reflected their host diversification in many instances, and at multiple taxonomic levels (Figures 2-4). Thus, CMVs infecting platyrrhines (New World monkeys) and catarrhines (apes and Old World monkeys) formed monophyletic groups, as did CMVs infecting members of the two catarrhine families represented in the trees (Cercopithecidae and Hominidae). Within these families, CMVs infecting members from the subfamilies Cercopithecinae and Colobinae were monophyletic, as were those infecting orangutans and African great apes. At an even lower taxonomic level, CMVs infecting monkeys belonging to the tribe Cercopithecini also formed a clade. Finally, when multiple CMVs were detected in a same host species, they generally formed monophyletic groups, i.e., CMVs found in Cercopithecus campbelli, Colobus guereza, Piliocolobus badius or Pongo pygmaeus. All in all, the comparison of the phylogenetic trees of CMV and their hosts therefore supported the notion that CMV diversification was strongly influenced by the diversity or diversification of their NHP hosts. 
Table 1. Cytomegalovirus (CMV) prevalence in nonhuman primates in Taï National Park, Côte d'Ivoire.

\begin{tabular}{|c|c|c|c|c|c|}
\hline Common Host Name & Host Species & Number of Individuals Tested & Number of Positives & $\%$ CMV Prevalence $\left(95 \% \mathrm{CI}^{\S}\right)$ & References \\
\hline Western chimpanzee & Pan troglodytes verus & $38(18 *)$ & $15(9 *)$ & $0.39(0.24-0.57)$ & [17] \\
\hline Sooty mangabey & Cercocebus atys & $37 *$ & $7 *$ & $0.19(0.09-0.36)$ & \\
\hline Western red colobus & Piliocolobus badius & $31(13 *)$ & $4(0 *)$ & $0.13(0.04-0.31)$ & [17] \\
\hline Black-and-white colobus & Colobus polykomos & $12(3 *)$ & $1(0 *)$ & $0.08(0.01-0.40)$ & [17] \\
\hline Diana monkey & Cercopithecus diana & $8^{*}$ & $1^{*}$ & $0.12(0.01-0.53)$ & \\
\hline Campbell's monkey & Cercopithecus campbelli & $4 *$ & $1 *$ & $0.25(0.01-0.78)$ & \\
\hline Potto & Perodicticus potto & $2 *$ & 0 * & $0(0-0.90)$ & \\
\hline Total & & 132 & 29 & 22 & \\
\hline
\end{tabular}

* Individuals tested in the current study; ${ }^{\S}$ Confidence interval.

Table 2. Cytomegaloviruses of nonhuman primates in Taï National Park, Côte d'Ivoire.

\begin{tabular}{|c|c|c|c|c|c|c|}
\hline Host Family and Species & Sample Number & Full Virus Name & Abbreviated Virus Name & UL55 Sequence $(\mathbf{k b})$ & References & Accession Number \\
\hline \multicolumn{7}{|l|}{ Hominidae } \\
\hline \multirow{7}{*}{ Pan troglodytes verus } & 9595 & & & 2.34 & \multirow{3}{*}{ Current study } & MG593784 \\
\hline & 9626 & & & 2.34 & & MG593786 \\
\hline & 9698 & Pan troglodytes cytomegalovirus 1 & PtroCMV1 & 2.36 & & MG593793 \\
\hline & 9722 & \multirow{4}{*}{ Pan troglodytes cytomegalovirus 2} & \multirow{4}{*}{ PtroCMV2 } & 2.34 & \multirow{4}{*}{$\begin{array}{c}{[10]} \\
\text { Current study } \\
{[10]}\end{array}$} & MG593797 \\
\hline & 3147 & & & 2.79 & & FJ538485 \\
\hline & 9622 & & & 2.39 & & MG593785 \\
\hline & 2296 & & & 1.83 & & FJ538487 \\
\hline \multicolumn{7}{|l|}{ Cercopithecidae } \\
\hline \multirow{8}{*}{ Cercocebus atys } & 9639 & \multirow{4}{*}{ Cercocebus atys cytomegalovirus 1} & \multirow{3}{*}{ CatyCMV1 } & 2.23 & \multirow{3}{*}{ Current study } & MG593787 \\
\hline & 9645 & & & 2.23 & & MG593788 \\
\hline & 9646 & & & 2.23 & & MG593789 \\
\hline & 9686 & & & 2.24 & & MG593791 \\
\hline & 9691 & Cercocebus atys cytomegalovirus 2 & CatyCMV2 & 2.25 & Current study & MG593792 \\
\hline & 9705 & & & 2.23 & & MG593794 \\
\hline & 9706 & Cercocebus atys cytomegalovirus 3 & CatyCMV3 & 0.20 & Current study & MG593795 \\
\hline & 9720 & Cercocebus atys roseolovirus 1 & CatyROV1 & 0.22 & Current study & MG593796 \\
\hline \multirow{2}{*}{ Cercopithecus campbelli } & 9726 & Cercopithecus campbelli cytomegalovirus 1 & CcamCMV1 & 2.24 & Current study & MG593798 \\
\hline & 9727 & Cercopithecus campbelli cytomegalovirus 2 & CcamCMV2 & 2.24 & Current study & MG593799 \\
\hline \multirow{2}{*}{ Cercopithecus diana } & 9657 & Cercopithecus diana cytomegalovirus 1 & CdiaCMV1 & 2.24 & \multirow{2}{*}{ Current study } & MG593790 \\
\hline & 6944 & Piliocolobus badius cytomegalovirus 1 & PbadCMV1 & 1.67 & & KF254800 \\
\hline \multirow[t]{2}{*}{ Piliocolobus badius } & 6940 & Piliocolobus badius cytomegalovirus 2 & PbadCMV2 & 1.67 & \multirow[t]{2}{*}{ [17] } & KF254799 \\
\hline & 4598 & Piliocolobus badius cytomegalovirus 3 & PbadCMV3 & 0.22 & & KF318790 \\
\hline
\end{tabular}


Table 3. Cytomegalovirus test results for organ and blood samples from nonhuman primates in Taï National Park, Côte d'Ivoire.

\begin{tabular}{|c|c|c|c|c|c|c|c|}
\hline Tissue & $\begin{array}{l}\text { Cercopithecus } \\
\text { diana }\end{array}$ & $\begin{array}{c}\text { Cercopithecus } \\
\text { campbelli }\end{array}$ & $\begin{array}{c}\text { Cercocebus } \\
\text { atys }\end{array}$ & $\begin{array}{c}\text { Colobus } \\
\text { polykomos }\end{array}$ & $\begin{array}{c}\text { Pan } \\
\text { troglodytes }\end{array}$ & $\begin{array}{c}\text { Piliocolobus } \\
\text { badius }\end{array}$ & $\begin{array}{l}\text { Perodicticus } \\
\text { poto }\end{array}$ \\
\hline Kidney & 2 & $2(1)$ & $5(1)$ & - & 1 & 2 & - \\
\hline Liver & 2 & 1 & $10(2)$ & 1 & $9(3)$ & 4 & 1 \\
\hline Spleen & 1 & 1 & $5(1)$ & 1 & $11(4)$ & 1 & 2 \\
\hline Whole blood & 2 & - & 9 & 2 & - & - & - \\
\hline Buffy coat & $-b$ & - & $2(1)$ & - & 1 & 7 & - \\
\hline Lymph node & - & 2 & $2(1)$ & - & $4(1)$ & 1 & - \\
\hline Total & $13(1)$ & $3(0)$ & $50(10)$ & $4(0)$ & $37(10)$ & $18(0)$ & $4(0)$ \\
\hline
\end{tabular}

${ }^{\mathrm{a}}$ number of samples tested; in parentheses: number of samples CMV-positive in betaherpesvirus-generic nested PCR; ${ }^{\mathrm{b}}$ hyphen: not available.

Table 4. Cytomegaloviruses in organs and blood of nonhuman primates in Taï National Park, Côte d'Ivoire.

\begin{tabular}{|c|c|c|c|c|c|c|c|c|c|}
\hline Host Family and Species & Spleen & $\begin{array}{l}\text { Blood/Buffy } \\
\text { Coat }\end{array}$ & $\begin{array}{l}\text { Lymph } \\
\text { Node }\end{array}$ & Heart & Lung & Kidney & Liver & Oesophagus & Duodenum \\
\hline \multicolumn{10}{|l|}{ Hominidae } \\
\hline Pan troglodytes verus & $\begin{array}{l}\text { PtroCMV1 a } \\
\text { PtroCMV2 }\end{array}$ & PtroCMV2 & PtroCMV1 & & PtroCMV1 & & $\begin{array}{l}\text { PtroCMV1 } \\
\text { PtroCMV2 }\end{array}$ & PtroCMV2 & - \\
\hline \multicolumn{10}{|l|}{ Cercopithecidae } \\
\hline Cercocebus atys & CatyCMV1 & CatyCMV2 & & CatyCMV3 & $\begin{array}{l}\text { CatyCMV1, } \\
\text { CatyCMV2 }\end{array}$ & $\begin{array}{l}\text { CatyCMV1, } \\
\text { CatyROV1 }\end{array}$ & $\begin{array}{l}\text { CatyCMV1, } \\
\text { CatyCMV2 }\end{array}$ & & - \\
\hline $\begin{array}{l}\text { Cercopithecus campbelli } \\
\text { Cercopithecus diana }\end{array}$ & - & - & - & - & $\stackrel{-}{-}$ & CcamCMV1 & - & - & CcamCMV2 \\
\hline Colobus polykomos & & & - & - & - & - & & - & - \\
\hline Perodicticus potto & & - & - & - & & - & & - & - \\
\hline Piliocolobus badius & & & & - & & - & & - & - \\
\hline
\end{tabular}

${ }^{a}$ sequences of the indicated viruses were obtained from PCR products generated with degenerate nested primers that are generic for members of the Betaherpesvirinae (PCR 1); hyphen: PCR negative. 


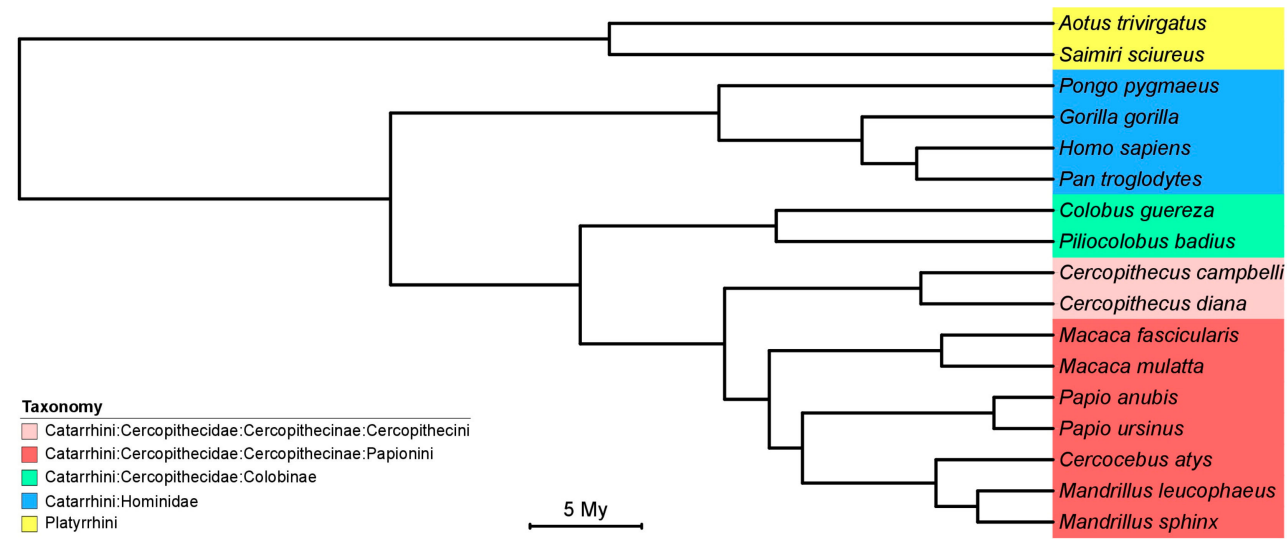

Figure 2. Time tree of nonhuman primate host species. This time tree was produced using a precompiled set of posterior trees available at the 10KTrees webserver [36]. Host common names are as follow: Aotus trivirgatus (three-striped night monkey), Cercocebus atys (sooty mangabey), Cercopithecus campbelli (Campbell's monkey), Cercopithecus diana (Diana monkey), Colobus guereza (guereza), Colobus polykomos (black-and-white colobus), Gorilla gorilla (Western lowland gorilla), Macaca fascicularis (cynomolgus monkey), Macaca mulatta (rhesus macaque), Mandrillus sphinx (mandrill), Mandrillus leucophaeus (drill), Pan troglodytes (chimpanzee), Papio anubis (olive baboon), Papio ursinus (chacma baboon), Piliolobus badius (western red colobus), Pongo pygmaeus (Borneo orangutan), Saimiri sciureus (common squirrel monkey).

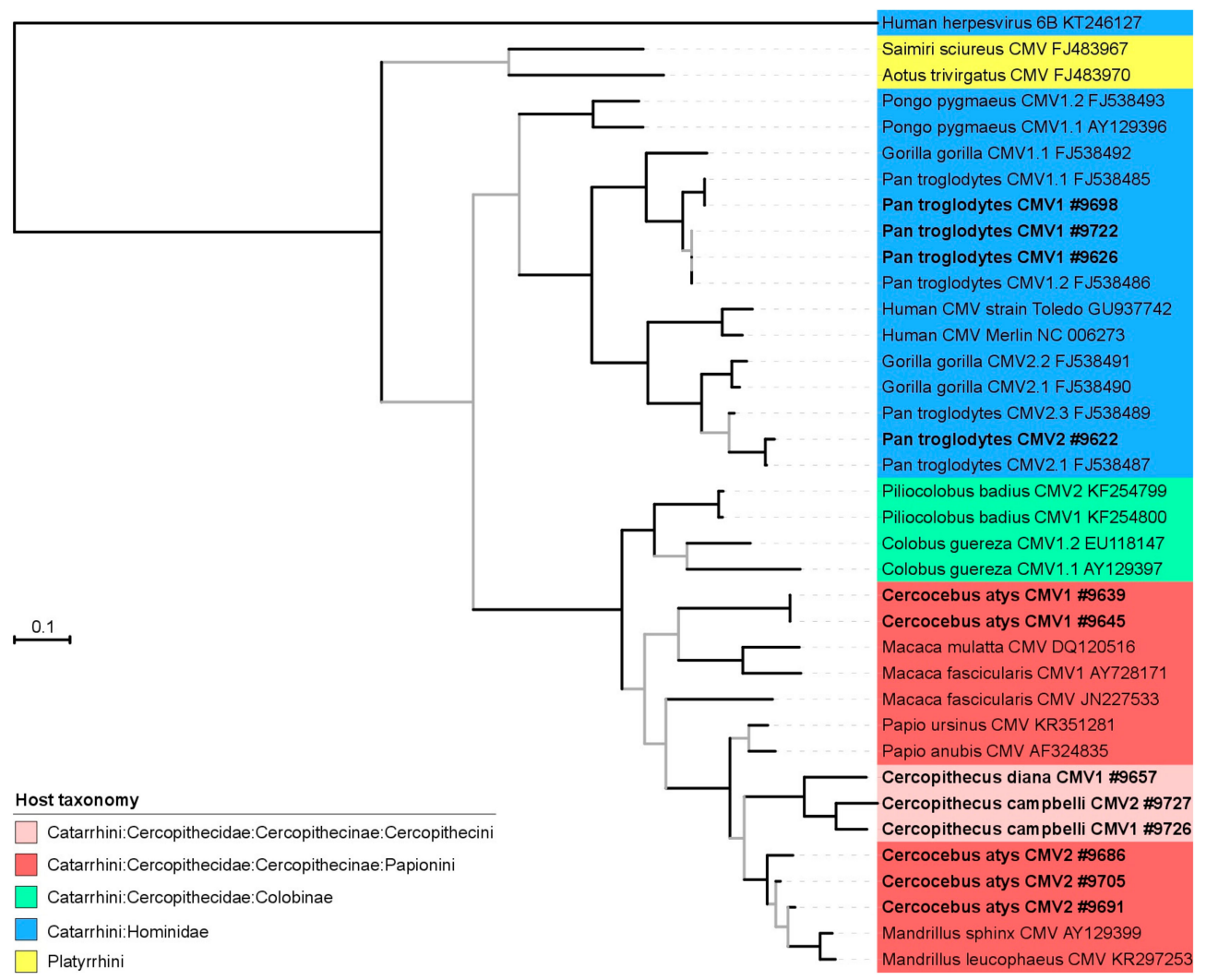

Figure 3. Maximum likelihood tree of partial CMV UL55 amino acid sequences. Sequences generated for this study are bold and displayed with their sample number (accession numbers in Table 1). Internal branches supported by Shimodaira-Hasegawa-like approximate likelihood ratio test (SH-like aLRT) values $<0.95$ are grey. The common names of the hosts after which the viruses are named are given in the legend of Figure 1. 


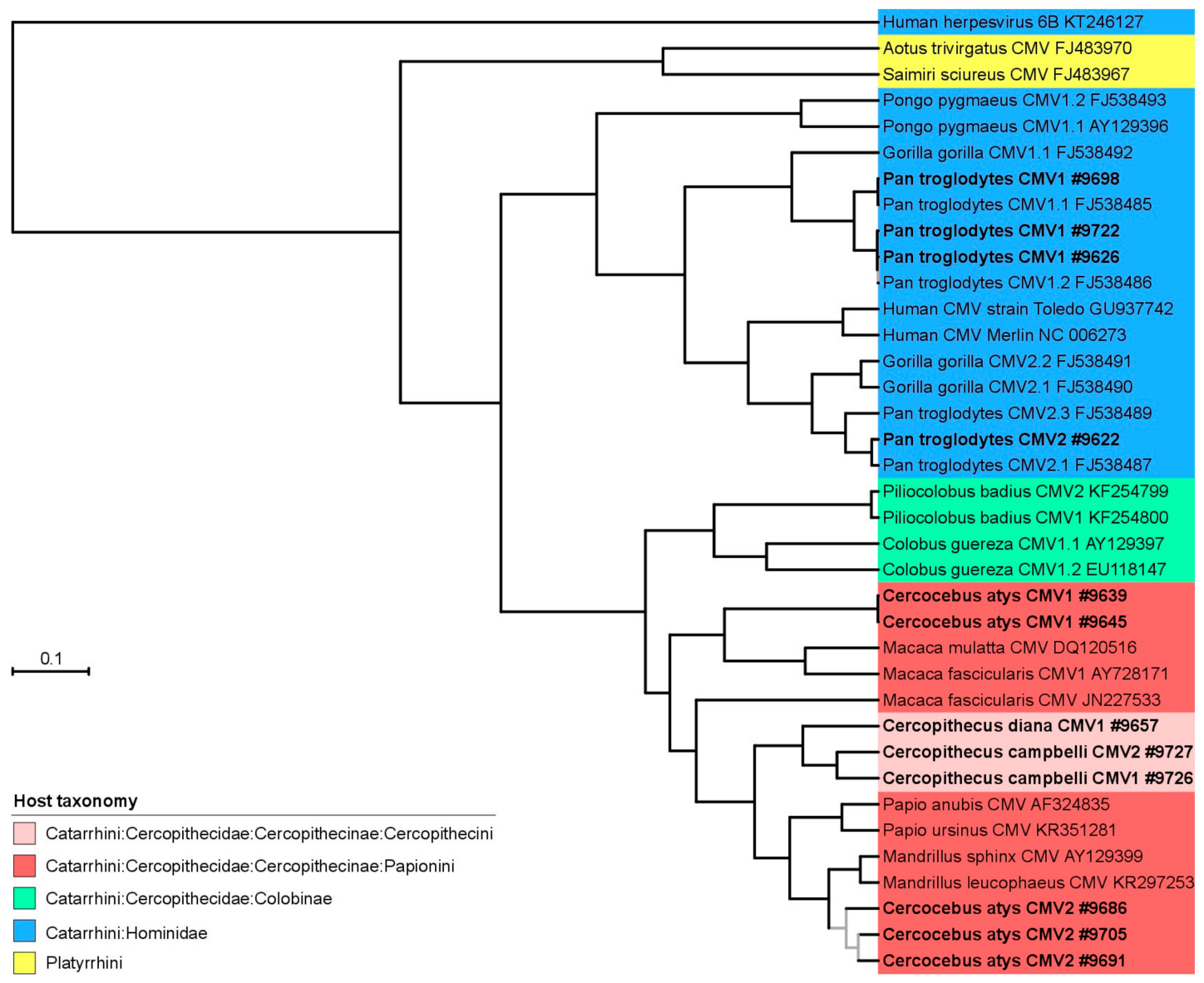

Figure 4. Bayesian Markov chain Monte Carlo tree of partial CMV UL55 amino acid sequences. Sequences generated for this study are bold and displayed with their sample number (accession numbers in Table 1). Internal branches supported by posterior probabilities $<0.95$ are grey. The common names of the hosts after which the viruses are named are given in the legend of Figure 1.

However, a number of exceptions were also observed in both ML and BMCMC CMV trees. As already pinpointed elsewhere, chimpanzees and gorillas appeared to be infected with CMVs belonging to a minimum of two lineages, suggesting either a viral lineage duplication event in the ancestor of African great apes or a more complex scenario involving multiple host switches between African great ape species [10]. Our phylogenetic analyses also showed that CMVs infecting Cercocebus atys belong to a minimum of two lineages, very distantly related to one another. In addition, CMVs infecting members of the Cercopithecini tribe, while exhibiting a phylogenetic placement that differed in the ML and BMCMC analyses, always disrupted the monophyly of CMVs infecting members of the Papionini tribe. This suggests again that pure co-divergence cannot fully explain the distribution of CMV genetic diversity in their hosts. Alternative processes, including lineage duplication, lineage loss and host switch are required to resolve discrepancies with the host phylogeny.

To further quantify the relative weight of co-speciation and these other processes during the diversification of NHP CMVs, we also ran explicit co-phylogenetic analyses. These analyses identified 8838 most parsimonious scenarios that all came at the same cost $(-16)$ and all involved 16 co-speciation events and 10 non co-speciation ones (tip mapping randomization test; $p=0$ ).

\section{Discussion}

Our systematic search for CMVs in the NHP community of TNP investigated seven NHP species. Eight CMVs were detected in four species, six of them novel and representing the first CMV detection 
in Cercocebus atys, Cercopithecus campbelli and Cercopithecus diana. Combined with the previous study of Murthy et al. on three NHP species in TNP [17], ten distinct CMVs were identified in six NHP species (Table 1 ). The only species for which no CMV could be identified was the potto but it was also the species for which sampling intensity was the lowest $(n=2)$. Collectively, these results therefore indicate that most NHP species in TNP are enzootically infected with CMVs.

In line with the moderate to high prevalence observed, we also found that three of the 17 CMV-positive NHP individuals (1 chimpanzee, 1 sooty mangabey, 1 Campbell's monkey) were infected with at least two different CMVs. This adds to accumulating evidence in the literature highlighting the commonness of superinfection with different CMVs in healthy people [38-40], chimpanzees [10,17], and rhesus macaques [41-43].

None of the eight CMVs detected in TNP infected more than one NHP species. This was also observed in previous studies led on wild NHPs: CMVs were only detected in their respective host species in chimpanzees, gorillas and two species of colobus monkeys $[10,17,18]$. However, our results considerably reinforce the notion that cross-species CMV transmission is at most rare in extending this observation to an entire primate community and to different modalities of NHP interactions. For example, a number of monkeys considered in this study form polyspecific groups, which could increase the likelihood of cross-species CMV transmission.

Our data also allowed us to investigate how the diversification patterns of CMVs and their hosts are correlated. Even considering the phylogenetic tree which was the least favorable to co-speciation events (the ML one) we found that co-divergence events dominate over non co-divergence events (61\% vs. $39 \%)$. Although we did not specifically investigate it, the comparison of relative divergence dates in the CMV and NHP trees seems suggestive of a similar diversification pace (even though not completely overlapping). It therefore seems likely that these apparent co-divergence events might indeed represent bona fide divergence events, pinpointing a very long-term association of these viruses and their hosts and measurable host tracking by CMVs. Interestingly, this mixture of diversification processes dominated by co-divergence seems to be relevant to a number of viruses with a double-stranded DNA genome, e.g., [44-46].

The combination of: (i) generally benign CMV infections in immunocompetent hosts; (ii) possibility to induce strain-specific immunity by superinfecting seropositive individuals with new CMVs; and (iii) apparent strong host-specificity has prompted efforts aimed at evaluating CMVs as platforms for self-disseminating vaccines. Recently, CMVs of NHPs have notably been considered as potential vaccine platform to protect NHPs in remote areas (and indirectly also humans) against cross-species transmission of lethal infectious agents such as ebolaviruses [47]. Although our ecological and evolutionary analyses of the distribution and diversification of CMVs in their natural hosts seem broadly compatible with the abovementioned prerequisites, they also pinpoint that non co-divergence events have left a measurable trace in the CMV phylogeny, which suggests that these approaches will at the very least require a very careful risk assessment.

Supplementary Materials: The following is available online at www.mdpi.com/1999-4915/10/1/11/s1, Table S1: Primers used for generic amplification of CMV UL55 and UL56 sequences; Table S2: Primers used for long-distance PCR amplification of CMV UL55/UL56 sequences.

Acknowledgments: This work was supported by the German Global Health G 7 Program. This work was only possible thanks to a long-term collaboration with the Taï Chimpanzee Project (TCP); we warmly thank the past and present directors of TCP, Christophe Boesch and Roman Wittig, the many veterinarians who performed necropsies, as well as Ariane Düx, Jan F. Gogarten and Alex Lang who collected blood from sooty mangabeys. We also thank the Ivorian authorities for their long-term support, especially the Ministry of the Environment and Forests as well as the Ministry of Research, the directorship of the Taï National Park and the Ivorian Office for Parks and Forests, and the Swiss Research Centre in Abidjan. Finally, we are very grateful to Cornelia Walter for her excellent technical assistance.

Author Contributions: C.A.-K., E.C.-H., F.H.L., S.C.-S. and B.E. conceived and designed the experiments; A.E.A. and S.M. performed the experiments; A.E.A. and S.C.-S. analyzed the data; A.E.A., S.C.-S. and B.E. drafted the paper; all authors critically commented on and approved the paper.

Conflicts of Interest: The authors declare no conflict of interest. 


\section{References}

1. Jabs, D.A. AIDS and ophthalmology, 2008. Arch. Ophthalmol. 2008, 126, 1143-1146. [CrossRef] [PubMed]

2. Lischka, P.; Zimmermann, H. Antiviral strategies to combat cytomegalovirus infections in transplant recipients. Curr. Opin. Pharmacol. 2008, 8, 541-548. [CrossRef] [PubMed]

3. Russell, M.Y.; Palmer, A.; Michaels, M.G. Cytomegalovirus infection in pediatric immunocompromised hosts. Infect. Disord. Drug Targets 2011, 11, 437-448. [CrossRef] [PubMed]

4. Vora, S.B.; Englund, J.A. Cytomegalovirus in immunocompromised children. Curr. Opin. Infect. Dis. 2015, 28, 323-329. [CrossRef] [PubMed]

5. Ho, M. The history of cytomegalovirus and its diseases. Med. Microbiol. Immunol. 2008, 197, 65-73. [CrossRef] [PubMed]

6. Rafailidis, P.I.; Mourtzoukou, E.G.; Varbobitis, I.C.; Falagas, M.E. Severe cytomegalovirus infection in apparently immunocompetent patients: A systematic review. Virol. J. 2008, 5, 47. [CrossRef] [PubMed]

7. Nassetta, L.; Kimberlin, D.; Whitley, R. Treatment of congenital cytomegalovirus infection: Implications for future therapeutic strategies. J. Antimicrob. Chemother. 2009, 63, 862-867. [CrossRef] [PubMed]

8. Heberling, R. Viral diseases of nonhuman primates in the wild. Lab. Anim. Sci. 1971, 21, 1019-1022. [PubMed]

9. Davison, A.J.; Dolan, A.; Akter, P.; Addison, C.; Dargan, D.J.; Alcendor, D.J.; McGeoch, D.J.; Hayward, G.S. The human cytomegalovirus genome revisited: Comparison with the chimpanzee cytomegalovirus genome FN1. J. Gen. Virol. 2003, 84, 17-28. [CrossRef] [PubMed]

10. Leendertz, F.H.; Deckers, M.; Schempp, W.; Lankester, F.; Boesch, C.; Mugisha, L.; Dolan, A.; Gatherer, D.; McGeoch, D.I.; Ehlers, B. Novel cytomegaloviruses in free-ranging and captive great apes: Phylogenetic evidence for bidirectional horizontal transmission. J. Gen. Virol. 2009, 90, 2386-2394. [CrossRef] [PubMed]

11. Hansen, S.G.; Strelow, L.I.; Franchi, D.C.; Anders, D.G.; Wong, S.W. Complete sequence and genomic analysis of rhesus cytomegalovirus. J. Virol. 2003, 77, 6620-6636. [CrossRef] [PubMed]

12. Marsh, A.K.; Willer, D.O.; Ambagala, A.P.; Dzamba, M.; Chan, J.K.; Pilon, R.; Fournier, J.; Sandstrom, P.; Brudno, M.; MacDonald, K.S. Genomic sequencing and characterization of cynomolgus macaque cytomegalovirus. J. Virol. 2011, 85, 12995-13009. [CrossRef] [PubMed]

13. Letvin, N.L.; Eaton, K.A.; Aldrich, W.R.; Sehgal, P.K.; Blake, B.J.; Schlossman, S.F.; King, N.W.; Hunt, R.D. Acquired immunodeficiency syndrome in a colony of macaque monkeys. Proc. Natl. Acad. Sci. USA 1983, 80, 2718-2722. [CrossRef] [PubMed]

14. Black, P.H.; Hartley, J.W.; Rowe, W.P. Isolation of a cytomegalovirus from African green monkey. Proc. Soc. Exp. Biol. Med. 1963, 112, 601-605. [CrossRef] [PubMed]

15. Blewett, E.; Lewis, J.; Gadsby, E.; Neubauer, S.; Eberle, R. Isolation of cytomegalovirus and foamy virus from the drill monkey (Mandrillus leucophaeus) and prevalence of antibodies to these viruses amongst wild-born and captive-bred individuals. Arch. Virol. 2003, 148, 423-433. [CrossRef] [PubMed]

16. Blewett, E.; White, G.; Saliki, J.; Eberle, R. Isolation and characterization of an endogenous cytomegalovirus (BaCMV) from baboons. Arch. Virol. 2001, 146, 1723-1738. [CrossRef] [PubMed]

17. Murthy, S.; Couacy-Hymann, E.; Metzger, S.; Nowak, K.; De Nys, H.; Boesch, C.; Wittig, R.; Jarvis, M.A.; Leendertz, F.H.; Ehlers, B. Absence of Frequent Herpesvirus Transmission in a Nonhuman Primate Predator-Prey System in the Wild. J. Virol. 2013, 87, 10651-10659. [CrossRef] [PubMed]

18. Seimon, T.A.; Olson, S.H.; Lee, K.J.; Rosen, G.; Ondzie, A.; Cameron, K.; Reed, P.; Anthony, S.J.; Joly, D.O.; McAloose, D. Adenovirus and herpesvirus diversity in free-ranging great apes in the Sangha region of the Republic of Congo. PLoS ONE 2015, 10, e0118543. [CrossRef]

19. Burwitz, B.J.; Malouli, D.; Bimber, B.N.; Reed, J.S.; Ventura, A.B.; Hancock, M.H.; Uebelhoer, L.S.; Bhusari, A.; Hammond, K.B.; Trethewy, R.G.E. Cross-Species Rhesus Cytomegalovirus Infection of Cynomolgus Macaques. PLoS Pathog. 2016, 12, e1006014. [CrossRef] [PubMed]

20. Lilja, A.E.; Shenk, T. Efficient replication of rhesus cytomegalovirus variants in multiple rhesus and human cell types. Proc. Natl. Acad. Sci. USA 2008, 105, 19950-19955. [CrossRef] [PubMed]

21. Swinkels, B.; Geelen, J.; Wertheim-van Dillen, P.; van Es, A.; van der Noordaa, J. Initial characterization of four cytomegalovirus strains isolated from chimpanzees. Arch. Virol. 1984, 82, 125-128. [CrossRef] [PubMed] 
22. Wroblewska, Z.; Gilden, D.; Devlin, M.; Huang, E.-S.; Rorke, L.B.; Hamada, T.; Furukawa, T.; Cummins, L.; Kalter, S.; Koprowski, H. Cytomegalovirus isolation from a chimpanzee with acute demyelinating disease after inoculation of multiple sclerosis brain cells. Infect. Immun. 1979, 25, 1008-1015. [PubMed]

23. Perot, K.; Walker, C.M.; Spaete, R.R. Primary chimpanzee skin fibroblast cells are fully permissive for human cytomegalovirus replication. J. Gen. Virol. 1992, 73, 3281-3284. [CrossRef] [PubMed]

24. Anoh, A.E.; Akoua-Koffi, C.; Couacy-Hymann, E.; Pauly, M.; Schubert, G.; Mossoun, A.; Weiss, S.; Leendertz, S.A.J.; Jarvis, M.A.; Leendertz, F.H.; et al. Genetic identification of cytomegaloviruses in a rural population of Côte d'Ivoire. Virol. J. 2015, 12, 155. [CrossRef] [PubMed]

25. Mossoun, A.; Pauly, M.; Akoua-Koffi, C.; Couacy-Hymann, E.; Leendertz, S.A.; Anoh, A.E.; Gnoukpoho, A.H.; Leendertz, F.H.; Schubert, G. Contact to Non-human Primates and Risk Factors for Zoonotic Disease Emergence in the Tai Region, Cote d'Ivoire. Ecohealth 2015, 12, 580-591. [CrossRef] [PubMed]

26. Ehlers, B.; Kuchler, J.; Yasmum, N.; Dural, G.; Voigt, S.; Schmidt-Chanasit, J.; Jakel, T.; Matuschka, F.R.; Richter, D.; Essbauer, S.; et al. Identification of novel rodent herpesviruses, including the first $\gamma$ herpesvirus of Mus musculus. J. Virol. 2007, 81, 8091-8100. [CrossRef] [PubMed]

27. Altschul, S.F.; Gish, W.; Miller, W.; Myers, E.W.; Lipman, D.J. Basic Local Alignment Search Tool. J. Mol. Biol. 1990, 215, 403-410. [CrossRef]

28. Edgar, R.C. MUSCLE: A multiple sequence alignment method with reduced time and space complexity. BMC Bioinform. 2004, 5, 113. [CrossRef] [PubMed]

29. Gouy, M.; Guindon, S.; Gascuel, O. SeaView version 4: A multiplatform graphical user interface for sequence alignment and phylogenetic tree building. Mol. Biol. Evol. 2010, 27, 221-224. [CrossRef] [PubMed]

30. Talavera, G.; Castresana, J. Improvement of phylogenies after removing divergent and ambiguously aligned blocks from protein sequence alignments. Syst. Biol. 2007, 56, 564-577. [CrossRef] [PubMed]

31. Darriba, D.; Taboada, G.L.; Doallo, R.; Posada, D. ProtTest 3: Fast selection of best-fit models of protein evolution. Bioinformatics 2011, 27, 1164-1165. [CrossRef] [PubMed]

32. Guindon, S.; Dufayard, J.F.; Lefort, V.; Anisimova, M.; Hordijk, W.; Gascuel, O. New algorithms and methods to estimate maximum-likelihood phylogenies: Assessing the performance of PhyML 3.0. Syst. Biol. 2010, 59, 307-321. [CrossRef] [PubMed]

33. Guindon, S.; Lethiec, F.; Duroux, P.; Gascuel, O. PHYML Online-A web server for fast maximum likelihood-based phylogenetic inference. Nucleic Acids Res. 2005, 33, W557-559. [CrossRef] [PubMed]

34. Anisimova, M.; Gil, M.; Dufayard, J.F.; Dessimoz, C.; Gascuel, O. Survey of branch support methods demonstrates accuracy, power, and robustness of fast likelihood-based approximation schemes. Syst. Biol. 2011, 60, 685-699. [CrossRef] [PubMed]

35. Drummond, A.J.; Suchard, M.A.; Xie, D.; Rambaut, A. Bayesian phylogenetics with BEAUti and the BEAST 1.7. Mol. Biol. Evol. 2012, 29, 1969-1973. [CrossRef] [PubMed]

36. Arnold, C.; Matthews, L.J.; Nunn, C.L. The 10kTrees website: A new online resource for primate phylogeny. Evol. Anthropol. Issues News Rev. 2010, 19, 114-118. [CrossRef]

37. Conow, C.; Fielder, D.; Ovadia, Y.; Libeskind-Hadas, R. Jane: A new tool for the cophylogeny reconstruction problem. Algorithms Mol. Biol. 2010, 5, 16. [CrossRef] [PubMed]

38. Novak, Z.; Ross, S.A.; Patro, R.K.; Pati, S.K.; Kumbla, R.A.; Brice, S.; Boppana, S.B. Cytomegalovirus strain diversity in seropositive women. J. Clin. Microbiol. 2008, 46, 882-886. [CrossRef] [PubMed]

39. Ross, S.A.; Arora, N.; Novak, Z.; Fowler, K.B.; Britt, W.J.; Boppana, S.B. Cytomegalovirus reinfections in healthy seroimmune women. J. Infect. Dis. 2010, 201, 386-389. [CrossRef] [PubMed]

40. Meyer-König, U.; Ebert, K.; Schrage, B.; Pollak, S.; Hufert, F.T. Simultaneous infection of healthy people with multiple human cytomegalovirus strains. Lancet 1998, 352, 1280-1281. [CrossRef]

41. Powers, C.; Frueh, K. Rhesus CMV: An emerging animal model for human CMV. Med. Microbiol. Immun. 2008, 197, 109-115. [CrossRef] [PubMed]

42. Hansen, S.G.; Vieville, C.; Whizin, N.; Coyne-Johnson, L.; Siess, D.C.; Drummond, D.D.; Legasse, A.W.; Axthelm, M.K.; Oswald, K.; Trubey, C.M.; et al. Effector memory T cell responses are associated with protection of rhesus monkeys from mucosal simian immunodeficiency virus challenge. Nat. Med. 2009, 15, 293-299. [CrossRef] [PubMed]

43. Hansen, S.G.; Powers, C.J.; Richards, R.; Ventura, A.B.; Ford, J.C.; Siess, D.; Axthelm, M.K.; Nelson, J.A.; Jarvis, M.A.; Picker, L.J.; et al. Evasion of CD8(+) T Cells Is Critical for Superinfection by Cytomegalovirus. Science 2010, 328, 102-106. [CrossRef] [PubMed] 
44. Buck, C.B.; Van Doorslaer, K.; Peretti, A.; Geoghegan, E.M.; Tisza, M.J.; An, P.; Katz, J.P.; Pipas, J.M.; McBride, A.A.; Camus, A.C.; et al. The Ancient Evolutionary History of Polyomaviruses. PLoS Pathog. 2016, 12, e1005574. [CrossRef] [PubMed]

45. Hoppe, E.; Pauly, M.; Gillespie, T.R.; Akoua-Koffi, C.; Hohmann, G.; Fruth, B.; Karhemere, S.; Madinda, N.F.; Mugisha, L.; Muyembe, J.J.; et al. Multiple Cross-Species Transmission Events of Human Adenoviruses (HAdV) during Hominine Evolution. Mol. Biol. Evol. 2015, 32, 2072-2084. [CrossRef] [PubMed]

46. Madinda, N.F.; Ehlers, B.; Wertheim, J.O.; Akoua-Koffi, C.; Bergl, R.A.; Boesch, C.; Akonkwa, D.B.; Eckardt, W.; Fruth, B.; Gillespie, T.R.; et al. Assessing Host-Virus Codivergence for Close Relatives of Merkel Cell Polyomavirus Infecting African Great Apes. J. Virol. 2016, 90, 8531-8541. [CrossRef] [PubMed]

47. Murphy, A.A.; Redwood, A.J.; Jarvis, M.A. Self-disseminating vaccines for emerging infectious diseases. Expert Rev. Vaccines 2016, 15, 31-39. [CrossRef] [PubMed]

(C) 2017 by the authors. Licensee MDPI, Basel, Switzerland. This article is an open access article distributed under the terms and conditions of the Creative Commons Attribution (CC BY) license (http://creativecommons.org/licenses/by/4.0/). 